\title{
A clinical study of maternal outcome in post dated pregnancy in a tertiary care hospital
}

\author{
Nikhil Anand*, Hardik Shah
}

Department of Obstetrics and Gynecology, Gujarat Medical Education and Research Society, Sola Civil Hospital, Sarkhej-Gandhinagar Highway, Sola, Ahmedabad, Gujarat, India

Received: 29 April 2019

Accepted: 01 July 2019

*Correspondence:

Dr. Nikhil Anand,

E-mail: anandnikhil81@yahoo.com

Copyright: (c) the author(s), publisher and licensee Medip Academy. This is an open-access article distributed under the terms of the Creative Commons Attribution Non-Commercial License, which permits unrestricted non-commercial use, distribution, and reproduction in any medium, provided the original work is properly cited.

\begin{abstract}
Background: Pregnancy lasting beyond 40 weeks is a known complication of normal delivery. Studies have found incidence between 2-14\%. Post-dated pregnancy carries specific hazards to both mother and fetus. While mothers are faced with problems like increased incidences of induced labour, instrumental delivery and LSCS with associated morbidities, fetuses are faced with morbidities ranging from IUGR to macrosomia. We here tried to study maternal outcome in post-dated pregnancy. The objective is to study maternal outcome in post-dated pregnancy and to compare maternal outcome in spontaneous versus induced labour in post-dated pregnancy.

Methods: This study was done at a tertiary care hospital in obstetrics and gynecology department for duration of 18 months. After screening according to inclusion criteria, all patients who were admitted in labour wards were grouped in two groups according to clinical examination. First group consists of patients with spontaneous onset of labour and second group consists of patients with induction of labour. In each group same protocol for fetal monitoring were performed, and labor monitored according to standard partograph. Maternal outcomes in both groups were studied.

Results: Maternal outcomes were nearly same in both groups; induced and spontaneous onset of labour, except rate of LSCS, Which was more in induced group though not statistically significant.

Conclusions: Women with uncomplicated post dated pregnancies with good bishop score should be allowed spontaneous labour and those with poor bishop should be offered induction of labour, while women with any complicating factors LSCS should be considered.
\end{abstract}

Keywords: Induction, LSCS, Maternal morbidity, Postdatism

\section{INTRODUCTION}

FIGO and WHO defined post term pregnancy as a pregnancy with has gestational length of 294 days or more. $^{1,2}$ Post maturity, post-term, Postdate, and prolonged pregnancy is accepted terms by WHO and the International Federation are of Gynecology and Obstetrics to describe pregnancy beyond dates (expected date of delivery). Prolongation of pregnancy complicates up to $10 \%$ of all pregnancies and carries increased risk to mother and fetus. 3,4
The incidence of post term pregnancy varies depending on whether the calculation is based on the history and clinical examination alone, or whether early pregnancy ultrasound examination is used to estimate gestational age. ${ }^{5,6}$

Estimation of gestational age is the foundation for diagnosis and subsequent management of postdated pregnancy. Primary method is by dating by LMP, with naegles rule according to which incidence of labor at or after 42 weeks is $14 \% .^{7}$ The assessment of the gestational 
age by early ultrasound examination has reduced the "incidence" of post term pregnancy by $50.0 \%{ }^{8}$

Complications to both mother and fetus are seen in postdated pregnancies. It has been reported that in a pregnancy which has crossed the expected date of delivery; there is an increased risk of oligohydramnios, meconium stained amniotic fluid, macrosomia, fetal post maturity syndrome, and cesarean delivery, all of which condition jeopardize the baby as well as the mother. Prolonged pregnancy has always been regarded as a highrisk condition because perinatal morbidity and mortality is known to rise. ${ }^{9}$

Vorherr described critical reductions of fetal oxygen supply after $43^{\text {rd }}$ week of gestation by cord blood oxygen content determinations. ${ }^{10}$ The maternal risks of post-dated pregnancy are often underappreciated. These include an increase in labor dystocia (9-12\% versus $2-7 \%$ at term), an increase in severe perineal injury $\left(3^{\text {rd }}\right.$ and $4^{\text {th }}$ degree perineal lacerations) related to macrosomia $(3.3 \%$ versus $2.6 \%$ at term) and operative vaginal delivery, and a doubling in the rate of cesarean delivery (14\% versus $7 \%$ at term). ${ }^{11-14}$ The latter is associated with higher risks of complications such as endometritis, hemorrhage, and thromboembolic disease. ${ }^{13,15}$

As there is fetal and maternal risk associated with postdated pregnancy, need of induction is more with postdated pregnancy. There are several recommendations for the postdate pregnancy management, but no protocol is considered as gold standard, so management varies from hospital to hospital and country to country. As such most of the studies studied fetal outcome in post-dated pregnancy very well as fetus is in jeopardized in postdatism, only a few studied maternal outcome which condition is also jeopardized as you can see from reported maternal complication. So we decided to study maternal outcome in postdate pregnancy and comparison of outcome in spontaneous with induced labour.

\section{METHODS}

This is a prospective cross-sectional study carried out in a tertiary care hospital for duration of 18 months from April 2015 to October 2016. Patients who attended ANC OPD and patients admitted in labor wards were included after screening through inclusion criteria.

\section{Inclusion criteria}

- Sure, of dates

- Who crossed the expected date of delivery by USG or LMP

- Singleton pregnancy

- Cephalic presentation

- One first or second trimester USG

- Unscarred uterus.
Total patients selected were 170 and divided under group 1 and group 2 according to the clinical examinations (mainly per vaginal and bishops score) of the patient.

Group 1 (spontaneous group) 85 patients with favourable bishops score.

Group 2 (induction group) 85 patients with unfavourable bishops score.

After assessment of bishops score every patient was studied in the respective group. On admission, ultrasound examination, non-stress test and biophysical profile test was done. In group 1 with good bishop score, patients were allowed spontaneous labour and labour monitored as per who criteria according to partograph.

In group 2 with low bishop score induction of labour done with intra-vaginal instillation of dinoprostone gel in posterior fornix with proper aseptic precautions after taking informed consent and excluding hypersensitivity. After 6 hours vaginal examination was repeated, if cervix was favourable than oxytocin augmentation done and if not favorable than repeat induction done with dinoprostone gel taking all precautions. After 6 hours again examination done, if cervix was found favourable than oxytocin augmentation done and if not favourable than LSCS done for failed induction.

In both groups labor abnormalities were identified by Freidman's criteria using partograph. Labor augmentation was done with amniotomy at $4-5 \mathrm{~cm}$ dilation and oxytocin as per need. If liquor was not clear (meconium stained) decision of LSCS taken as per FHR monitoring in both groups. According to mode of delivery outcome was studied.

\section{Statistical analysis}

Chi square test and $\mathrm{p}$ value is used as a measure to find out stastical significance.

\section{RESULTS}

Table 1: Distribution of cases according to maternal age.

\begin{tabular}{|lll|}
\hline Age in years & Number of patients & Percentage \\
\hline$<20$ & 41 & 24.11 \\
\hline $20-30$ & 117 & 68.82 \\
\hline$>30$ & 12 & 7.06 \\
\hline Total & $\mathbf{1 7 0}$ & $\mathbf{1 0 0}$ \\
\hline Mean \pm SD & $24.12 \pm 4.13$ & \\
\hline
\end{tabular}

As seen in Table 1 majority of patients belong to age group 20-30 years $(68.82 \%)$ followed by $<20$ years. Only $7.06 \%$ were above 30 years of age. The mean value of total was 24.12 years and SD of 4.13. Mean age as 24.21 
years with SD of 4.46 in group 1 and 24.02years with SD of 3.81 in group 2.

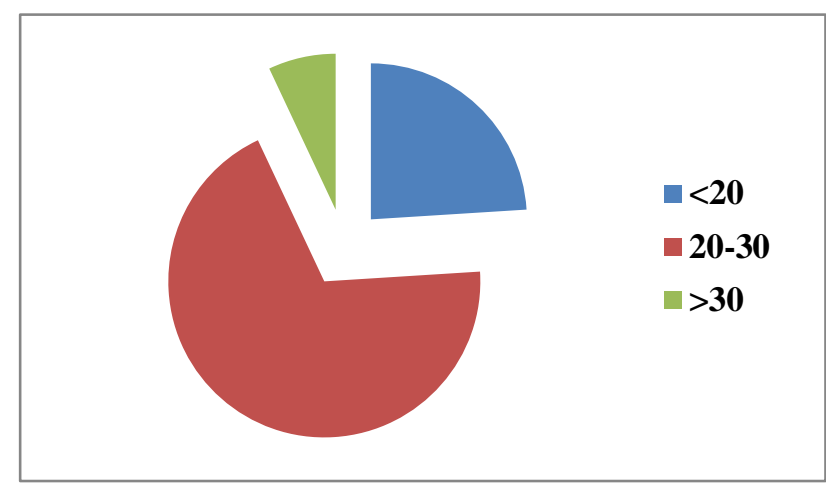

Figure 1: Distribution of patients according to age.

Figure 1 shows the graphical presentation of the cases according to age. We can see clearly that large chunk of the patients are between 20 to 30 years of age.

Table 2: Distribution of cases according to booked /unbooked basis.

\begin{tabular}{|lll|}
\hline Booked /unbooked & Number & Percentage \\
\hline Booked & 77 & 45.29 \\
\hline Unbooked & 93 & 54.70 \\
\hline Total & $\mathbf{1 7 0}$ & $\mathbf{1 0 0}$ \\
\hline P value & & 0.220 \\
\hline
\end{tabular}

As we can see from Table 2 number of cases presented were almost equal between booked and unbooked category. There is no statically significant difference between booked and unbooked cases.

Table 3: Distribution of cases according to gestational age.

\begin{tabular}{|lll|}
\hline Gestational age & By dates & By USG \\
\hline $40-40$ w 6 d & No. $(\boldsymbol{\%})$ & No. $(\boldsymbol{\%})$ \\
\hline $41-41$ w 6 d & $62(36.47)$ & $72(42.35)$ \\
\hline 42 and $>42$ & $86(50.58)$ & $96(56.47)$ \\
\hline Total & $22(12.94)$ & $2(1.17)$ \\
\hline Mean \pm SD & $\mathbf{1 7 0}(\mathbf{1 0 0})$ & $\mathbf{1 7 0}(\mathbf{1 0 0})$ \\
\hline
\end{tabular}

This Table 3 shows that when gestational age was calculated by first ultrasound, $42.35 \%$ cases were $<41$ weeks and $56.47 \%$ were between 41-41weeks 6 days, while only $1.17 \%$ were at or beyond 42 weeks. Similarly when GA was calculated by dates (LMP) $36.47 \%$ were $<41$ weeks and $50.58 \%$ were between 41-41weeks 6 days, while $12.94 \%$ were at or beyond 42 weeks.

From the above Table 4 we can find out that majority of patients $(71.8 \%$ in group 1 and $66 \%$ in group 2) were delivered vaginally with no stastical significant $\mathrm{p}$ value ( $p=0.644$ ) between two groups. Out of 170 patients $69 \%$ were delivered vaginally $28 \%$ by LSCS and in $3 \%$ it was instrumental delivery.

Table 4: Distribution of cases according to mode of delivery.

\begin{tabular}{|lllllll|}
\hline \multirow{2}{*}{ Mode of delivery } & Group 1 & & Group 2 & Total & Percent \\
\hline Vaginal & No. & Percent & No. & Percent & No. & 68.82 \\
\hline Instrumental & 61 & 71.76 & 56 & 65.88 & 117 & 2.94 \\
\hline LSCS & 2 & 2.35 & 3 & 3.52 & 5 & 28.23 \\
\hline Total & 22 & 25.88 & 26 & 30.58 & 48 & $\mathbf{1 0 0}$ \\
\hline
\end{tabular}

Table 5: Distribution of cases according to indication of LSCS.

\begin{tabular}{|lllllll|}
\hline Indication Of LSCS & Group 1 & & Group 2 & \multicolumn{2}{l|}{ Total } \\
\hline Fetal distress & No. & \% & No. & \% & No. & \% \\
\hline Non progress of labour & 12 & 54.545 & 9 & 34.615 & 21 & 43.75 \\
\hline Failure of induction & 10 & 45.45 & 8 & 34.265 & 18 & 37.499 \\
\hline Total & - & - & 9 & 34.6615 & 9 & 18.75 \\
\hline
\end{tabular}

As depicted above in Table 5 main indication for LSCS in both groups was fetal distress followed by non progress of labour while failure of induction was also a contributing reason in group 2.

As we can conclude from the given Table 6, out of 170 patients $14(16.47 \%)$ in group 1 and $15(17.64 \%)$ in group 2 were having maternal morbidity. Common were prolonged labour and fever in both the groups. Other morbidities include perineal injuries and psychological problems.

From the graphical representation seen in Figure 2 it is seen that both group 1 and 2 are nearly same when 
comparing various morbidities related to maternal outcome. As shown in Table 7, majority of patients were having favorable maternal outcome (82.94\%).
Unfavorable outcome which included maternal morbidity accounts for $17.05 \%$.

Table 6: Distribution of cases according to maternal morbidity.

\begin{tabular}{|llllllll|}
\hline \multirow{2}{*}{ Maternal morbidity } & Group1 & \multicolumn{9}{c|}{ Group 2} & \multicolumn{3}{c|}{ Total } \\
\hline Prolonged labour & No. & $\mathbf{\%}$ & No & $\mathbf{\%}$ & No & \% & P value \\
\hline PPH & 4 & 28.57 & 5 & 33.33 & 9 & 31.03 & 0.739 \\
\hline Fever & 3 & 21.42 & 2 & 13.33 & 5 & 17.24 & 0.65 \\
\hline Wound infection & 3 & 21.42 & 4 & 26.66 & 7 & 24.13 & 0.705 \\
\hline Others & 2 & 14.28 & 3 & 20 & 5 & 17.24 & 0.65 \\
\hline Total & 2 & 14.28 & 1 & 6.66 & 3 & 10.34 & 0.61 \\
\hline
\end{tabular}

Table 7: Distribution of cases according to maternal outcome.

\begin{tabular}{|llllllll|}
\hline \multirow{2}{*}{ Maternal outcome } & Group1 & \multicolumn{9}{c}{ Group 2 } & \multicolumn{3}{c|}{ Total } & P value \\
\cline { 2 - 9 } & No. & \% & No. & \% & No. & \% & 0.58 \\
\hline Favorable & 71 & 83.52 & 70 & 82.35 & 141 & 82.94 & 0.705 \\
\hline unfavorable & 14 & 16.47 & 15 & 17.64 & 29 & 17.05 & \\
\hline Total & $\mathbf{8 5}$ & $\mathbf{1 0 0}$ & $\mathbf{8 5}$ & $\mathbf{1 0 0}$ & $\mathbf{1 7 0}$ & $\mathbf{1 0 0}$ & \\
\hline
\end{tabular}

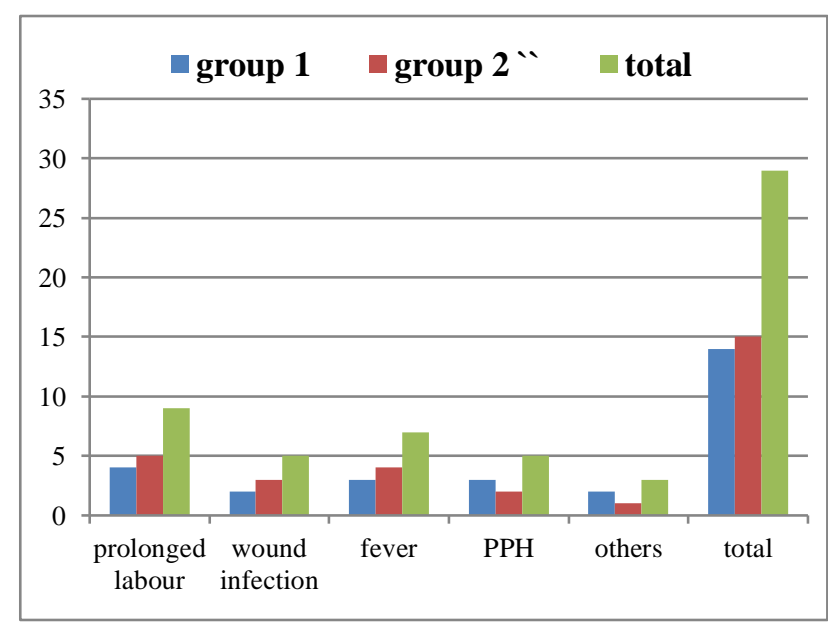

Figure 2: Distribution of cases according to maternal morbidity.

\section{DISCUSSION}

Our study was done in tertiary care hospital in obstetrics and gynecology department. The study duration was 18 months. 170 patients who were past their expected date of delivery were studied after screening by inclusion criteria. In our study majority of patients were below 30 years of age. Alexander $\mathrm{J}$ et al, found similar results with most of the patients were between 20-30 years of age group and mean gestational age in group 1 $24.4 \pm 5.3$ years and in group 2, 24 \pm 5.3 years. ${ }^{16}$ Women who are of advance maternal age are at greater risk of still birth throughout gestation, the greatest risk period is 37 to 41 weeks. $^{17}$
In our study the mean gestational age was total 41.18 weeks with SD of 0.85 , while if we see according to groups than in group 1 it was 41.19 weeks with SD of 0.89 while in group 2 it was 41.18 with SD of 0.81 . When gestational age as calculated by ultrasound majority of cases were $<42$ weeks $(98.83 \%)$ and only $1.17 \%$ were $\geq$ 42 weeks. Alexander J et al, advocated similar results. ${ }^{16}$ There was no stastical significant $\mathrm{p}$ value in both groups in consideration with maternal morbidity. Maternal morbidity in total was $17.05 \%$. In the studies carried out by Singh $\mathrm{P}$ et al, (11.8\% versus $13.8 \%)$ also found no statically significant differences. ${ }^{18}$ There was no statistical significant $\mathrm{p}$ value in group 1 and group2 in consideration with maternal outcome. Alexander $\mathbf{J}$ et al, and Singh $\mathrm{P}$ et al, quoted similar results in their study. ${ }^{16,18}$ One recent systematic review showed that a policy of labor induction for women with postdated pregnancy compared with expectant management is associated with fewer perinatal deaths and fewer caesarean sections. ${ }^{19}$

\section{CONCLUSION}

The timely onset of labor is an important determinant of perinatal outcome. Confirmation of diagnosis of postdatism is very important. It should be done by first trimester USG, along with LMP. In management of postdatism a careful advice and proper monitoring can alleviate maternal anxiety and untoward complications.

Perinatal morbidity and mortality is centered on adequacy of finding better methods for recognizing high-risk fetus, the ideal time for testing, monitoring method, optimum time and mode for delivery. The availability of 
biophysical profile and electronic fetal monitoring can affect the maternal and fetal outcome.

After 41 weeks of gestation if the dates are confirmed women should be offered elective delivery. Women with uncomplicated pregnancies should be offered induction of labour, while women with any complicating factors LSCS should be considered. The adverse outcome can be reduced by making accurate gestational age and diagnosis of postterm gestation as well as recognization and management of risk factors.

Funding: No funding sources

Conflict of interest: None declared

Ethical approval: Not required

\section{REFERENCES}

1. WHO: recommended definitions, terminology and format for statistical tables related to the perinatal period and use of a new certificate for cause of perinatal deaths. Modifications recommended by FIGO as amended October 14, 1976. Acta Obstet Gynecol Scand. 1977;56(3):247-53.

2. Report of the FIGO subcommittee on perinatal epidemiology and health statistics following a workshop on the methodology of measurement and recording of infant growth in perinatal period. Cairo. November 11 to 18,1984 . International Federation of Gynecology and Obstetrics (FIGO). London. Int J Gynecol Obstet. 1986;24:483.

3. Olesen AW, Westergaard JG, Olsen J. Perinatal and maternal complications related to postterm delivery: a national register-based study, 1978-1993. Am J Obstet Gynecol. 2003;189:2227.

4. Norwitz ER, Snegovskikh VV, Caughey AB. Prolonged pregnancy: when should we intervene? Clin Obstet Gynecol. 2007;50:547-57.

5. Eik-Nes SH, Okland O, Aure JC, Ulstein M. Ultrasound screening in pregnancy: A randomised controlled trial. Lancet. 1984;1:1347.

6. Ingemarsson I, Hedén L. Cervical score and onset of spontaneous labor in prolonged pregnancy dated by second-trimester ultrasonic scan. Obstet Gynecol. 1989;74:102-5.

7. Manning FA, Platt LD, Sips L, Keegan KA. Fetal breathing movements and non stress test in high risk pregnancies. Am J obstet Gynaecol. 1979;135:511-5.

8. Marahatta R, Tuladhar H, Sharma S. Comparative study of post term and term pregnancy in Nepal
Medical College Teaching Hospital (NMCTH). Nepal Med Coll J. 2009;11:57-60.

9. Grant JM. Induction of labour confers benefits in prolonged pregnancy. $\mathrm{Br} \mathrm{J}$ Obstet Gynaecol. 1994;101:99-102.

10. Vorherr H. Placental insuffiency in relation to postterm pregnancy and fetal postmaturity: Evaluation of fetoplacental function Management of post term gravida. Am J Obstet Gynecol. 1975;123:67.

11. Rand L, Robinson JN, Economy KE. Post-term induction of labor revisited. Obstet Gynecol. 2000;96(5 Pt 1):779-83.

12. Campbell MK, Ostbye T, Irgens LM. Post-term birth: risk factors and outcomes in a 10-year cohort of Norwegian births. J Obstet. Gynecol. 1997;89(4):543-8.

13. Alexander JM, McIntire DD, Leveno KJ. Forty weeks and beyond: pregnancy outcomes by week of gestation. Obstet Gynecol. 2000;96(2):291-4.

14. Treger M, Hallak M, Silberstein T. Post-term pregnancy: should induction of labor be considered before 42 weeks? J Maternal Fetal Neonatal Med. 2002;11(1):50-3.

15. Eden RD, Seifert LS, Winegar A. Perinatal characteristics of uncomplicated postdate pregnancies. Obstet Gynecol. 1987;69:296-9.

16. Alexander J, Macer CL, Chan LS. Elective induction versus spontaneous labour: A prospective study of complications and outcome. Am J Obstet Gynecol. 1992;166:1690-7.

17. Reddy UM, KO CW, Willinger M. Maternal age and risk of stillbirth throughout pregnancy in the United States. Am J Obstet Gynecol. 2006;195(3):764-70.

18. Singhal P, Sharma A, Jain S, Pandey V. Fetomaternal outcome following postdate pregnancya prospective study. J Obst Gynecol Ind. 2001;51(5):89-93.

19. Gulmezoglu AM, Crowther CA, Middleton P. Induction of labour for improving birth outcomes for women at or beyond term. Cochrane Database Syst Rev. 2012;6:CD00494.

Cite this article as: Anand N, Shah $\mathrm{H}$. A clinical study of maternal outcome in post dated pregnancy in a tertiary care hospital. Int J Reprod Contracept Obstet Gynecol 2019;8:3573-7. 